\title{
sciendo
}

Current Issues in Pharmacy and Medical Sciences

Formerly ANNALES UNIVERSITATIS MARIAE CURIE-SKIODOWSKA, SECTIO DDD, PHARMACIA

journal homepage: http://www.curipms.umlub.pl/

\section{Casirivimab and imdevimab as investigational monoclonal antibodies for COVID-19 patients - review of the literature}

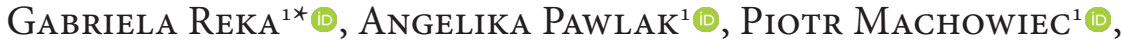 \\ Marcela Maksymowicz ${ }^{1}{ }^{\oplus}$, Halina Piecewicz-SzCZesna $^{2}{ }^{\circledR}$
}

${ }^{1}$ Students' Scientific Association of Chair and Department of Epidemiology and Clinical Research Methodology, Medical University of Lublin, Poland

${ }^{2}$ Chair and Department of Epidemiology and Clinical Research Methodology, Medical University of Lublin, Poland

\section{ARTICLE INFO}

Received 29 March 2021

Accepted 20 August 2021

\section{Keywords:}

COVID-19,

REGN-COV-2,

casirivimab,

imdevimab

monoclonal antibodies.

\begin{abstract}
Casirivimab and imdevimab (REGN-COV-2) are investigational monoclonal antibodies approved in November 2020 by the Food and Drug Administration for emergency use in mild and moderate COVID-19. These two noncompeting human IgG1 monoclonal antibodies can target the receptor-binding domain of the spike protein of SARS$\mathrm{CoV}-2$, prevent its entry into human cells, and reduce viral load. The antibodies can be administered intravenously for mild-to-moderate COVID-19 patients who do not require hospitalization and supplemental oxygen. The purpose of the study is to review the latest available data on COVID-19 treatment using casirivimab and imdevimab. According to recent preclinical studies, the antibody cocktail presents optimal antiviral strength and has the potential to minimize the chances of the virus escaping. It was shown in animal studies that the cocktail reduces the pathological consequences caused by viruses, decreases the number of viruses in the respiratory system, and reduces lung titers and pneumonia symptoms. Casirivimab and imdevimab as a cocktail also prevents the rapid appearance of treatment-resistant mutants. In the clinical trial, REGN-COV-2 decreased viral load, particularly in patients with a non-initiated immune response (serum antibody-negative) and with high viral load at baseline. The adverse effects were comparable in the combined REGN-COV2 dose groups ( $2.4 \mathrm{~g}$ and $8.0 \mathrm{~g}$ ), as well as in the placebo group. The cocktail caused few and mainly low-grade toxic effects. Casirivimab and imdevimab seem to be effective and safe antiviral therapy for nonhospitalized patients with COVID-19. Further observations and research are extremely necessary to assess the efficacy, security and indications in a wider group of patients.
\end{abstract}

\section{INTRODUCTION}

The outbreak of the novel coronavirus SARS-CoV-2 pandemic prompted researchers from all over the world to search for safe and effective drugs. Casirivimab and imdevimab, also known as REGN-COV-2 (REGN10933 and REGN10987), are investigational monoclonal antibodies produced for the first time in the United States that were approved in November 2020 by the Food and Drug Administration (FDA) for emergency use in mild and moderate COVID-19 [1-4]. Casirivimab and imdevimab are two novel recombinant virus-neutralizing human subclass IgG1 monoclonal antibodies $[5,6]$. Their mechanism of action is based on the ability to target the receptor-binding domain (RBD)

\footnotetext{
* Corresponding author

e-mail: gabrysia.reka@gmail.com
}

of the spike protein of SARS-CoV-2 [7-9]. In February 2021, the European Medicines Agency (EMA) made its recommendations on the use of casirivimab and imdevimab in the antibody cocktail [7].

The study aims to review the latest available data on COVID-19 treatment using monoclonal antibodies casirivimab and imdevimab.

\section{MATERIAL AND METHODS}

A review of the latest literature until 26 February, 2021 was made. Studies published in English and available as full-text publications are included. The data was collected from the PubMed and Google Scholar platforms using the following keywords: "REGN-COV2", "casirivimab AND 
imdevimab", "monoclonal antibodies AND cocktail AND COVID-19". Original and review papers were referred to, whereas letters to the editor and preprints were excluded. After reading abstracts, 15 papers that met the adopted criteria, were selected for analysis.

\section{RESULTS}

\section{Fundamentals and mechanism of action}

Monoclonal antibodies ( $\mathrm{mAb}$ ) are proteins produced in a laboratory that imitate or strengthen the immune system [3]. Casirivimab and imdevimab are obtained from parallel efforts using both B cells from recovered COVID-19 patients and transgenic, genetically engineered mice [2]. REGN-COV2 consists of two noncompeting human IgG1 monoclonal antibodies - REGN10933 and REGN10987 $[5,9,10]$. They are likely to help reduce the viral load (amount of virus in the back of the throat and nose) [11]. The antibody cocktail prevents SARS-CoV-2 entry into human cells through the receptor of angiotensin-converting enzyme 2 (ACE2) by targeting the receptor-binding domain of the viral spike protein [5]. The main target of neutralizing antibody development is RBD, which is responsible for binding host cell receptors [12]. As a result, SARS-CoV-2 will not be able to attach to receptors that are on the surface of the host cell [11].

REGN10933 and REGN10987 can recognize distinct and non-overlapping epitopes on the RBD and simultaneously bind to them. Cocktail treatments might preserve their capability to neutralize mutant strains with $\mathrm{S}$ variants and reduce antibody escape [10]. The epitope for REGN10933 is located at the top of the RBD, whereas REGN10987 binds on the side of the RBD and almost does not overlap with the ACE2 binding site [13]. Casirivimab and imdevimab are diluted and administered as a single intravenous infusion [3].

There is a hypothesis that in a severe course of COVID19 , the complications and death from it result from the SARS-CoV-2 viral burden. Diminishing this burden should be of clinical benefit. The long half-life of REGN-COV2 could potentially result in passive immunity for several months, because concentrations of the drug in serum at day 29 in $>95 \%$ of patients were well above the predicted neutralization target concentration [5].

\section{Indications and contraindications}

According to the FDA, casirivimab and imdevimab can be administered intravenously together for mild-tomoderate COVID-19 patients at the age of at least 12 years and weighing not less than $40 \mathrm{~kg}$. They are indicated for patients at high risk for progressing to severe COVID-19 and/or hospitalization and with positive results of direct SARS-CoV-2 viral testing [1-3,6]. It is recommended for use within 10 days after onset of symptoms of outpatients and the suffering from comorbid diseases that increase the risk of a severe course of COVID-19 [8,11]. Risk factors include conditions, such as obesity, cardiovascular and respiratory diseases, chronic kidney and liver diseases, diabetes mellitus, immunosuppressive diseases or receiving immunosuppressive therapy $[7,8]$.
In case of the necessity of hospitalization due to severe symptoms of COVID-19 or long-term care - hospice or comfort care, administration of casirivimab and imdevimab is not possible [4]. Also, if a patient requires oxygen therapy due to not only SARS-CoV-2 infection, but various diseases needs, and in whom an increase in oxygen supply is warranted because of the severity of COVID-19, the use of monoclonal antibodies is contraindicated [3]. The situation is similar in patients with a severe course of COVID-19, requiring high-flow oxygen or mechanical ventilation due to the possible deterioration of the disease caused by antibodies $[3,6]$. Moreover, patients with allergy or hypersensitivity to casirivimab, imdevimab, or any components of the infusion fluid should not receive it $[5,7]$.

\section{Results of preclinical and clinical research}

Hansen et al. conducted a preclinical study in which humanized mice and B cells from convalescent humans were used to produce antibodies against the coronavirus spike protein 2 (SARS-CoV-2). Therein, a large and diverse collection of fully human antibodies having different sequences, antiviral activity, and binding properties was isolated. Two methods were used to produce anti-SARSCoV-2 spike antibodies. One method was to immunize the tested mice with plasmid DNA that expresses SARS-CoV-2 spike protein. The next step was to boost with a recombinant protein that consisted of the SARS-CoV-2 spike RBD. The second method was to isolate antibodies from convalescent peripheral blood mononuclear cells (PBMCs). A total of over 200 antibodies were isolated that neutralized vesicular stomatitis virus (VSV)-based SARS-CoV-2 pseudoparticles at a concentration $>70 \%$ from $\sim 2 \mu \mathrm{g} / \mathrm{ml}$ of expressed antibodies. Four antibodies were selected for further analyses. This work indicated that in the highly neutralizing SARSCoV-2 monoclonal antibodies, there are extended traps of typical rearrangements. The chosen antibody cocktail has the potential to minimize the chances of the virus escaping and presents optimal antiviral strength [13].

In the preclinical in vivo research made by Baum et al., the effectiveness of the REGN-COV-2 cocktail in the treatment of SARS-CoV-2 infections was assessed therapeutically or prophylactically in rhesus macaques and golden hamsters. This cocktail consists of two potent fully human neutralizing antibodies (REGN10933 and REGN10987) [14]. The study demonstrated the significant antiviral activity of the REGN-COV2 cocktail in reducing the viral load, in the case of prophylactic administration and improving viral clearance when administered for therapeutic purposes $[5,14]$. Baum et al. revealed that, as compared to placebo, administering REGN-COV-2 to rhesus macaques that presented a mild clinical course of the disease, brought about accelerated clearance of genomic RNA (gRNA) with almost complete ablation of subgenomic RNA (sgRNA) in the vast majority of animals subjected to the study. Furthermore, the cocktail was found to reduce the pathological consequences that are caused by viruses and that it was possible to significantly diminish the number of viruses in their respiratory system. It was also observed that administration of the cocktail three days before viral challenge minimized virus replication, even when challenged with a 10 -fold higher 
viral inoculum. In addition, in golden hamsters with more severe symptoms, the cocktail reduced lung titers, as well as pneumonia symptoms and minimized weight loss [14].

In another preclinical study conducted with a surrogate virus in vitro, Baum et al. showed that REGN10933 and REGN10987 antibody cocktail neutralizes all then known viral mutants, even the ones that were selected for by treatment with only one of its components. They noted that individual use of an antibody may lead to selective pressure and the emergence of novel viral mutations. With use of a cocktail, rapid selection for mutants would require the improbable occurrence of simultaneous viral mutation at two different genetic sites, which would enable SARS-CoV-2 to escape from neutralization by both antibodies. According to the study, casirivimab and imdevimab as a cocktail prevented the fast emergence of treatment-resistant mutants [15].

In a randomized, double-blind, placebo-controlled, phase 1-3 clinical trial, Weinreich et al. evaluated the outcomes of 275 patients $>18$ years of age with confirmed COVID-19 and symptoms from maximal 7 days before randomization who did not require hospitalization. In this multicenter and still ongoing trial, patients received intravenously throughout 1 hour saline placebo, $2.4 \mathrm{~g}$ of REGN-COV2, or $8.0 \mathrm{~g}$ of REGN-COV2 in a 250-ml normal saline solution. Both casirivimab and imdevimab were given in equal doses in the cocktail.

At the beginning of the study, patients were categorized according to the presence of preexisting antibodies against SARS-CoV-2 as serum antibody-negative or serum antibody-positive (at least one of the following: IgA anti-S1 domain of spike protein, IgG anti-S1 domain of spike protein, or IgG anti-nucleocapsid protein). Time-weighted mean alteration in viral load from baseline through day 7 and the percent of patients with at least one COVID-19 - related medically attended visit through day 29 were considered as end points. Outcomes from the phase 1-2 portion of the trial indicated that REGN-COV2 decreased viral load, particularly in patients with not initiated immune response (serum antibody-negative) and with high viral load at baseline. Viral loads and a probability of having a medically attended visit were lowered among participants in the serum antibodypositive subgroup, in comparison with the serum antibodynegative subgroup [5].

In the EMA document, further results of a randomized, double-blind, placebo-controlled clinical trial (NCT04425629), were presented. The study included 799 adult patients who had a confirmed SARS-CoV-2 infection, symptoms of COVID19 $\leq 7$ days from the time of randomization, had never received COVID-19 therapy, or were hospitalized for COVID-19 treatment, and maintained $\mathrm{O}_{2}$ saturation $\geq 93 \%$ room air. Patients were divided into three groups ( $\mathrm{n}=266, \mathrm{n}=267, \mathrm{n}=266$ ), in which they received intravenous infusions consisting of $2.400 \mathrm{mg}$ casirivimab and imdevimab in equal amounts, $8,000 \mathrm{mg}$ cesirivimab and imdevimab in equal amounts, or placebo. All participants taking REGN-COV2 had significant reductions in viral load (assessed by quantitative RT-qPCR through day 7), mostly in seronegative patients at baseline and in patients with high viral load. A fewer number of patients from REGN-COV2 groups had medically attended visits, COVID-19 related hospitalization, and emergency room visits compared to a placebo group. Symptom improvement was seen after a mean of 5 days for patients with $\geq 2$ risk factors treated with REGN-COV2 and 11 days for placebo [7]. The summary of described studies is presented in the table below (Table 1).

Table 1. Characteristics of studies included in the review

\begin{tabular}{|c|c|c|c|}
\hline Authors & $\begin{array}{l}\text { Type of } \\
\text { study }\end{array}$ & $\begin{array}{l}\text { Studied material/ } \\
\text { research group }\end{array}$ & Results and conclusions \\
\hline $\begin{array}{l}\text { Hansen et al. } \\
(2020) \text { [13] }\end{array}$ & preclinical & $\begin{array}{l}\text { monoclonal antibodies } \\
\text { against SARS-CoV-2 } \\
\text { (containing casirivimab } \\
\text { and imdevimab) } \\
\text { produced by humanized } \\
\text { mice and B cells from } \\
\text { convalescent humans }\end{array}$ & \begin{tabular}{|l|} 
In the highly \\
neutralizing SARS- \\
CoV-2 monoclonal \\
antibodies, there are \\
extended traps of \\
typical rearrangements. \\
The antibody cocktail \\
has the potential to \\
minimize the chances \\
of the virus escaping. \\
Moreover, it presents \\
optimal antiviral \\
strength
\end{tabular} \\
\hline $\begin{array}{l}\text { Baum et al. } \\
\text { (2020) [14] }\end{array}$ & preclinical & $\begin{array}{l}\text { casirivimab and } \\
\text { imdevimab used in } \\
\text { rhesus macaques and } \\
\text { golden hamsters }\end{array}$ & $\begin{array}{l}\text { REGN-COV2 cocktail } \\
\text { presents antiviral } \\
\text { activity in reducing } \\
\text { the viral load, in the } \\
\text { case of prophylactic } \\
\text { administration, it also } \\
\text { improves viral clearance } \\
\text { when administered for } \\
\text { therapeutic purposes, } \\
\text { reduces the pathological } \\
\text { consequences that } \\
\text { are caused by viruses, } \\
\text { the number of viruses } \\
\text { in the respiratory } \\
\text { system, lung titers, and } \\
\text { pneumonia symptoms }\end{array}$ \\
\hline $\begin{array}{l}\text { Baum et al. } \\
\text { (2020) [15] }\end{array}$ & preclinical & \begin{tabular}{|l|} 
casirivimab and \\
imdevimab used against \\
surrogate virus in vitro
\end{tabular} & $\begin{array}{l}\text { Casirivimab } \\
\text { and imdevimab } \\
\text { administered as } \\
\text { a cocktail prevents the } \\
\text { fast emergence of the } \\
\text { treatment-resistant } \\
\text { mutants }\end{array}$ \\
\hline $\begin{array}{l}\text { Weinreich } \\
\text { et al. } \\
\text { (2021) [5] }\end{array}$ & clinical & $\begin{array}{l}275 \text { patients }>18 \text { years } \\
\text { of age with confirmed } \\
\text { cOVID- } 19 \text { who did not } \\
\text { require hospitalization } \\
\text { receiving placebo, } 2.4 \\
\text { g, or } 8.0 \mathrm{~g} \text { of REGN- } \\
\text { cov2 }\end{array}$ & $\begin{array}{l}\text { REGN-COV2 decreased } \\
\text { viral load, particularly } \\
\text { in patients with not } \\
\text { initiated immune } \\
\text { response and with } \\
\text { high viral load at } \\
\text { baseline. Probability } \\
\text { of having a medically } \\
\text { attended visit lowered } \\
\text { among participants in } \\
\text { the serum antibody- } \\
\text { positive subgroup, } \\
\text { in comparison with } \\
\text { the serum antibody- } \\
\text { negative subgroup }\end{array}$ \\
\hline
\end{tabular}

\section{Safety of the antibodies' use}

In the clinical trial by Weinreich et al., the aspect of antibodies' safety was raised. Alluding to this study comparing the percentages of patients with adverse events in the combined REGN-COV2 dose groups ( $2.4 \mathrm{~g}$ and $8.0 \mathrm{~g}$ ), as well as in the placebo group, it was observed that these percentages were similar. The REGN-COV2 antibodies' safety profile was as predicted for a fully human antibody against an exogenous target [5]. Nevertheless, casirivimab and imdevimab may only be administered together [1]. Their separate use (for the treatment of COVID-19) is not authorized by Emergency Use Authorizations (EUAs) due to the lack of evidence of efficacy and compliance with safety requirements.

As confirmed in the study by Weinreich et al., both REGN-COV2 doses (2.4 g and $8.0 \mathrm{~g}$ ) demonstrated few and mainly low-grade toxic effects [5]. Reported adverse 
effects include infusion-related reactions, such as weakness, fever, chills, hives, itching and flushing $[3,7]$. Regarding more serious events (grade three or four), most frequently these were pneumonia, hyperglycemia, nausea, vomiting $(2.4 \mathrm{~g})$, as well as intestinal obstruction and dyspnea $(8.0 \mathrm{~g})$ [8]. In case of overdose with REGN-COV2, it is necessary to monitor vital signs and give symptomatic treatment with histidine [7]. Hypersensitivity reactions, including anaphylaxis, can be resolved with epinephrine [8]. However, infusion of casirivimab-imdevimab should take place in the hospital, where it is possible to assess a patient's clinical condition [7].

Due to the limited studies, there is no full information about the safety of using antibodies during pregnancy and breastfeeding. Influence on fertility and interactions with other medicinal products have not yet been fully known [7]. Currently, there is no data on the use and safety of REGNCOV2 cocktails in children with COVID-19 [6,7].

\section{Current and further perspectives}

Rapid introduction on the market of new medicinal products in the time of the COVID-19 pandemic for emergency use is possible, but requires pre-clinical and clinical trials, as well as the approval of appropriate institutions. However, there is a risk that pharmaceutical companies and governments might press on FDA and EMA to fast register and introduce novel medicinal products for emergency use. The cocktail of casirivimab and imdevimab is one of several investigational methods of treatment allowed to be used during the pandemic. The search for new applications of previously known drugs or the production of new drugs is important in the context of awaiting the widespread distribution of COVID-19 vaccines.

\section{CONCLUSIONS}

Casirivimab and imdevimab seem to be promising, effective and safe antiviral therapy for nonhospitalized patients with COVID-19. Further observations concerning different groups of patients and clinical trials are extremely necessary to confirm the efficacy in a wider group of patients and potentially expand the indications for their use. Reliance on the facts arising from scientific research according to the evidence-based medicine rules becomes of great importance during the current pandemic.

\section{ORCID iDs}

Gabriela Ręka (1)https://orcid.org/0000-0001-9728-5281

Angelika Pawlak (1) https://orcid.org/0000-0003-4130-2593

Piotr Machowiec (Dhttps://orcid.org/0000-0002-5418-0110

Marcela Maksymowicz (D) https://orcid.org/0000-0003-2611-1609 Halina Piecewicz-Szczęsna

(D)https://orcid.org/0000-0002-0573-7226

\section{REFERENCES}

1. Rizk JG, Forthal DN, Kalantar-Zadeh K, Mehra MR, Lavie CJ, Rizk Y, et al. Expanded Access Programs, compassionate drug use, and Emergency Use Authorizations during the COVID-19 pandemic. Drug Discov Today. 2021;26(2):593-603.

2. Kaplon H, Reichert JM. Antibodies to watch in 2021. MAbs. 2021; 13(1):1860476.

3. Aschenbrenner DS. Monoclonal antibodies receive EUA to treat mild to moderate COVID-19. Am J Nurs. 2021;121(2):26.

4. Tulledge-Scheitel S, Bell SJ, Larsen JJ, Bierle DM, Takahashi P, Moehnke DE, et al. A mobile unit overcomes the challenges to monoclonal antibody infusion for COVID-19 in skilled care facilities. J Am Geriatr Soc. 2021;69(2):868-73.

5. Weinreich DM, Sivapalasingam S, Norton T, Ali S, Gao H, Bhore R, et al. REGN-COV2, a neutralizing antibody cocktail, in outpatients with Covid-19. N Engl J Med. 2021;384(3):238-51.

6. Wolf J, Abzug MJ, Wattier RL, Sue PK, Vora SB, Zachariah P, et al. Initial guidance on use of monoclonal antibody therapy for treatment of COVID-19 in children and adolescents. J Pediatric Infect Dis Soc. 2021:10(5):629-34.

7. Conditions of use casirivimab and imdevimab (REGN-COV2). Annex I. Conditions of use, conditions for distribution and patients targeted and conditions for safety monitoring addressed to member states for unauthorized product available for use. European Medicines Agency, 26 February 2021. (https://www.ema.europa.eu/en/documents/ referral/regn-cov2-antibody-combination-casirivimab/imdevimabcovid-19-conditions-use-conditions-distribution-patients-targetedconditions-safety_en.pdf) [accessed on 26 February 2021]

8. Pallotta AM, Kim C, Gordon SM, Kim A. Monoclonal antibodies for treating COVID-19. Cleeve Clin J Med. 2021. [online ahead of print]

9. Starr TN, Greaney AJ, Addetia A, Hannon WW, Choudhary MC, Dingens AS, et al. Prospective mapping of viral mutations that escape antibodies used to treat COVID-19. Science. 2021;371(6531):850-4.

10. Jiang S, Zhang X, Yang Y, Hotez PJ, Du L. Neutralizing antibodies for the treatment of COVID-19. Nat Biomed Eng. 2020;4:1134-9.

11. Deb P, Molla MMA, Rahman KMS. An update to monoclonal antibody as therapeutic option against COVID-19. Biosaf Health. 2021;3(2):87-91.

12. Sun Y, Ho M. Emerging antibody-based therapeutics against SARSCoV-2 during the global pandemic. Antib Ther. 2020;3(4):246-256.

13. Hansen J, Baum A, Pascal KE, Russo V, Giordano S, Wloga E, et al. Studies in humanized mice and convalescent humans yield a SARSCoV-2 antibody cocktail. Science. 2020;369:1010-4.

14. Baum A, Ajithdoss D, Copin R, Zhou A, Lanza K, Negron N, et al. REGN-COV2 antibodies prevent and treat SARS-CoV-2 infection in rhesus macaques and hamsters. Science. 2020;370(6520):1110-5.

15. Baum A, Fulton BO, Wloga E, Copin R, Pascal KE, Russo V, et al. Antibody cocktail to SARS-CoV-2 spike protein prevents rapid mutational escape seen with individual antibodies. Science. 2020; 369(6506):1014-8. 